\title{
Effects of headings and familiarity with a text on strategies for searching a text
}

\author{
MADELINE A. KLUSEWITZ and ROBERT F. LORCH, JR. \\ University of Kentucky, Lexington, Kentucky
}

\begin{abstract}
College students were videotaped while they searched chapter-length texts for answers to specific questions. The texts either did not contain headings or contained one of three types of headings that varied in the information that they provided about text organization and content. Familiarity with the text was varied by manipulating (1) the number of prior searches of the text and (2) whether or not the text was read before searching. Measures were taken of the time spent examining each page and of the sequence of examination of pages. Cluster analyses of the search measures revealed that familiarity with the text influenced a searcher's strategy for selecting which pages to examine. Once a page was selected for examination, both headings and familiarity influenced how the page was inspected.
\end{abstract}

Individuals in a literate society are constantly confronted with more information than they have time to carefully process. To cope efficiently with the overload of information, people must develop strategies for locating relevant information and ignoring irrelevant information. In fact, locating information in texts and other documents is the most common type of text processing task in occupational settings (Guthrie, Siefert, \& Kirsch, 1986; Mikulecky, 1982; Sticht, 1975).

Educational researchers have been particularly interested in document search, concentrating much of their efforts on determining the characteristics of an efficient search strategy. Their studies have demonstrated that search is facilitated by the use of access devices external to the text, such as a table of contents and subject index (Dreher, 1992; Dreher \& Guthrie, 1990; Symons \& Pressley, 1993; Yussen, Stright, \& Payne, 1993). Furthermore, efficient searchers spend proportionately more of their search time consulting such devices than do inefficient searchers (Dreher \& Guthrie, 1987, 1990; Dreher \& Sammons, 1994; Guthrie, 1988; Guthrie, Britten, \& Barker, 1991).

The focus of this study deviates from that of most previous research. Our goals were to identify the variety of text search strategies used by college students and to determine how their choice of strategy changes with increasing knowledge of the text. Our orienting hypothesis was that the availability of a representation of the text's topics and their organization is critical to the development

This study is based on a dissertation submitted by M.A.K. to the University of Kentucky in partial fulfillment of the requirements for the PhD. M. Klusewitz Campbell is now at Womble, Carlyle, Sandridge, \& Rice, 200 West Second Street, P. O. Box 84, Winston-Salem, NC 27102. Several colleagues provided valuable comments on earlier drafts of this manuscript. We thank Mike Masson, Morton Gernsbacher, Steve Hagemoser, Scott Johnston, Jennifer Klebaur, Erin Murphy, Elizabeth Lorch, and Eric Stephens. Correspondence concerning this manuscript should be directed to R. F. Lorch, Jr., Department of Psychology, University of Kentucky, Lexington, KY 40506-0044 (e-mail: rlorch@pop.uky.edu). of an efficient, selective search strategy (Kintsch \& van Dijk, 1978; Lorch, 1989). Once a topic structure representation has been constructed, the searcher has an internal access device that can guide selection of the approximate location of target information (i.e., page turning) and can facilitate the processing of any page selected for inspection (i.e., page inspection). Given this hypothesis, we chose to study two types of variables that could influence readers' representations of a text's topic structure. First, we varied readers' familiarity with a text by manipulating whether or not the text had previously been read and by manipulating the number of times the text had previously been searched. Second, we manipulated the type of headings present in the text.

\section{Effects of Familiarity}

Most research on text search has focused on search of a text that has not been read. Furthermore, although researchers generally require participants to perform multiple searches through the same text, practice effects have typically been ignored (McGoldrick, Martin, Bergering, \& Symons, 1992; Symons \& Pressley, 1993). Yet familiarity with a text is likely to greatly influence a person's search of the text.

One way in which familiarity with a text should facilitate search is by speeding the processing of any page chosen for inspection during the search. Although there are no reports of the effects of prior exposure to a text on text search, there is extensive literature on repeated reading of text. When the text and task remain unchanged across readings, reading speed increases with successive readings. This result has been observed in a variety of procedures, including reading aloud (Carr, Brown, \& Charalambous, 1989; Levy, Barnes, \& Martin, 1993; Levy \& Burns, 1990; Levy, Masson, \& Zoubek, 1991; Whittlesea, 1990), silent reading (Levy et al., 1995), sentence-by-sentence and word-by-word presentation (Millis, Simon, \& tenBroek, 1998), and eye-tracking experiments (Hyönä, 1995; Hyönä 
\& Niemi, 1990; Raney \& Rayner, 1995; Rayner, Raney, \& Pollatsek, 1995). The eye-tracking studies demonstrate that rereading is faster than initial reading because fixated content is processed more rapidly and because less content is fixated (i.e., some skimming occurs), (Hyönä \& Niemi, 1990; Raney \& Rayner, 1995). Given these results, we anticipated that searchers would inspect a page faster if they had previously read or searched the text than if the text had been completely unfamiliar.

Familiarity also can be expected to influence how searchers select pages for examination. When reading a text for comprehension, readers closely attend to topicintroducing sentences and compute their relationships to previously established text topics (Hyönä, 1995; Lorch, Lorch, \& Matthews, 1985; Lorch, Lorch, \& Mogan, 1987). Upon rereading the text, processing of topic sentences is facilitated more than processing of nontopic sentences (Hyönä, 1995; see also Mayer, 1983, and Millis et al., 1998). These findings have been interpreted as demonstrating that readers construct a representation of the text's topics and its organization as they read (Gernsbacher, 1990, 1997; Lorch et al., 1985). The availability of a topic structure representation should have a substantial influence on text search because it can be used to guide the reader's page turning strategy. If the text is unfamiliar, searchers must begin with the first page and inspect each successive page until they locate the target information. In contrast, searchers who are familiar with the text can consult their topic structure representations and estimate the page on which the target information is likely to be located. If they fail to find the target information on the first page they turn to, they can compare the topic(s) on that page to their topic structure representations in order to compute their next page turn. Thus, searchers who are familiar with a text can use a page-skipping strategy instead of an exhaustive page-turning strategy.

\section{Effects of Headings}

The effects of headings on text search have not been extensively researched (but see Hartley \& Trueman, 1985), despite the fact that college students indicate that they find headings useful when looking for specific information (Yussen et al., 1993). However, headings have been shown to facilitate readers' encoding of a text's topic structure (Lorch \& Lorch, 1995) and to guide both summarization and recall of text content (Lorch \& Lorch, 1996a, 1996b; Lorch, Lorch, \& Inman, 1993). Because headings help readers to construct a topic structure representation, they should support the development of efficient pageturning strategies. In addition, headings should facilitate page inspection.

Headings provide at least three types of information that may be useful during a search. First, headings demarcate distinct content in the text (i.e., section information), so they can be used to guide the process of sampling information on a page chosen for inspection. Second, headings provide a topic label that provides a searcher with information about the likely content of a text section (i.e., content information). Thus, headings can be used to make a decision about whether to examine a text section at all. Finally, the use of multiple-level headings provides information about the hierarchical relations among topics in a text (i.e., organization information). This information might be used to more rapidly locate the part of the text (e.g., first or second half of the text) that is likely to contain the target information.

Four headings conditions were constructed for the purpose of separating out the different possible uses of headings during a search. As is illustrated in Table 1, the structure headings condition demarcated the separate sections

Table 1

Corresponding Sections of the Same Text as Examples of the Four Headings Conditions

The text begins with two brief paragraphs to introduce the general theme, then the first half of the text discusses "energy problems." The examples below illustrate the nature of the headings manipulation for the first page and a half of the text. Only the initial sentence of each subsection is included in these examples.

Structure Headings Condition:

\section{ENERGY PROBLEMS}

The fossil fuels of coal, oil and gas share several important characteristics that helped establish them as favored sources of energy ..

\section{A. DWINDLING FUEL RESOURCES}

Coal, oil, gas, and radioactive minerals are certainly abundant natural resources ...

\section{(1) HAZARDOUS PRODUCTION METHODS}

One implication of our dwindling fossil fuel reserves is that methods of production are becoming increasingly hazardous...

Topic Headings Condition:

\section{ENERGY PROBLEMS}

The fossil fuels of coal, oil and gas share several important characteristics that helped establish them as favored sources of energy ... DWINDLING FUEL RESOURCES

Coal, oil, gas, and radioactive minerals are certainly abundant natural resources...

\section{HAZARDOUS PRODUCTION METHODS}

One implication of our dwindling fossil fuel reserves is that methods of production are becoming increasingly hazardous ...

Section Headings Condition:

$* * * * * * * *$

The fossil fuels of coal, oil and gas share several important characteristics that helped establish them as favored sources of energy ... $* * * * * * * *$

Coal, oil, gas, and radioactive minerals are certainly abundant natural resources,.

$* * * * * * * *$

One implication of our dwindling fossil fuel reserves is that methods of production are becoming increasingly hazardous.

No Headings Condition:

The fossil fuels of coal, oil and gas share several important characteristics that helped establish them as favored sources of energy ...

Coal, oil, gas, and radioactive minerals are certainly abundant natural resources...

One implication of our dwindling fossil fuel reserves is that methods of production are becoming increasingly hazardous . 
of the text, labeled the topics of each section, and provided information about the hierarchical relations among the topics via the use of typographical cues. Thus, structure headings provided section, content, and organization information. The topic headings condition provided section and content information but eliminated the typographical cues used in the structure headings condition that visually communicated the hierarchical structure of the text. The section headings condition demarcated only the sections of the text. Finally, there was a baseline condition with no headings of any kind. Comparisons of the four headings conditions should allow us to determine which of the three types of information would be used by searchers to select pages for examination and to inspect a page once it had been selected.

\section{Overview of the Task}

College students were videotaped as they searched through texts to locate specific answers to questions (Symons \& Pressley, 1993; Symons \& Specht, 1994). In order to determine the effects of familiarity and headings on page inspection, the mean time between successive page turns was recorded (i.e., look time). Several variables were included to determine the nature of the effects of familiarity and headings on page turning. The starting point of a search was operationalized as the loci of the first and second look at the text. In order to assess how searchers perused a text, we recorded the proportion of page turns corresponding to single-page advances, jumps of more than one page, and looks back to previous pages. The set of dependent measures provided a comprehensive profile of the nature of a participant's search strategy.

\section{METHOD}

\section{Participants}

The participants were 128 students enrolled in introductory or developmental psychology courses at the University of Kentucky. All participants were native English speakers and all received course credit for their participation. The participants were assigned at random to the four headings conditions, with the restriction that an equal number participated in each condition.

\section{Materials}

Two expository texts were written for the search task; one text was about energy use and the other was about fire fighting and prevention. Each text was hierarchically structured with two superordinate topics (e.g., energy problems and energy solutions), three topics organized under each of the two superordinate topics (e.g. dwindling fuel resources, environmental damage, and health problems), and anywhere from two to six subtopics under each secondlevel topic. The energy text was 13 single-spaced pages long; the fire text was 14 single-spaced pages long.

Four different versions of each text were constructed. The only differences between these versions were the types of headings available (see Table 1). In the structure headings condition, the headings representing the topmost level of the text structure were centered in the middle of the page, capitalized, and numbered with Roman numerals. The headings representing the middle level of structure were left justified, capitalized, and were preceded by a capitalized letter. The headings at the lowest level of structure were indented and capitalized, and they included a number in parentheses.
In the topic headings condition, the heading labels were the same as in the structure headings condition, except that no hierarchical cues were provided. All numbers and letters representing order were removed, and all headings were left justified.

For the section headings condition, topic information was removed from the headings by replacing the content heading labels with a string of asterisks.

In the no-headings condition, there were no headings or section markers of any sort. For this version, the only signal available was paragraph breaks.

The four versions of the two texts were assembled into separate notebooks. Each text contained a title page followed by the 13 or 14 unnumbered pages of the text. Individual pages were covered with a clear, plastic page protector to make it easier to turn the pages and to keep the pages intact. Different-colored construction paper was used as backing for each page, and a single, randomly chosen letter was written on the backing. This was done to facilitate the scorer's identification of pages from the videotape.

In addition to the notebooks containing the texts, other notebooks were constructed containing the questions for the search task. The notebook for the practice text contained three questions. The notebooks for the two critical texts contained five questions each. Only the first and last questions were analyzed; the middle three questions were fillers. Each question was located on a separate page in the notebook.

The critical questions were constructed to include key words from the (structure and content) subheading for the text section containing the target sentence. For example, one question was as follows: "In order for ocean thermal power to work, what has to be deployed in the ocean?" The phrase "ocean thermal power" corresponded to a subheading in the structure and topic headings conditions. This was done in order to provide maximal discrimination between search strategies that were based on a representation of the text's topic structure and those that were not. Most of the filler questions did not contain key words from the subheading for the section containing the target. This was done in order to prevent the participants in the structure and content headings conditions from developing a search strategy that relied solely on inspection of headings.

The answer to each question was always contained in a single sentence. For example, the target sentence containing the answer to the question about ocean thermal power was the following: "Very large pipes, up to 4,000 feet long, would have to be deployed in the ocean for some OTP designs." The target sentences were all located on the second- or third-to-last page of the text. This was done to allow maximal discrimination between the search strategies that proceeded page by page from the start of the text and the strategies that involved selective sampling of pages. The answers to the filler questions were located in earlier sections of the texts. The two critical questions regarding a text were always the first and fifth questions. Assignment of the critical questions to testing positions was counterbalanced across participants. The three filler questions were always presented in the same order.

\section{Procedure}

The participants were tested individually in a videotaped session that typically lasted about $45 \mathrm{~min}$. The participants were seated at a table containing the practice text and the question notebook. They were instructed to locate the answer to each question quickly and accurately, even if they knew the answer without searching. For each question, the participants began their search on the title page. In order to facilitate the scorer's task, the participants were asked to turn over pages completely so that they were lying in a horizontal position. The participants were to point to the target sentence when they located it so that the experimenter would know that the search had been completed. When the practice text was completed, the participants were given the two experimental texts.

The procedure for the two experimental texts was identical to that for the practice text, except that one of the two experimental texts 
was read "for comprehension" before the search task was administered. We counterbalanced the assignment of the two texts to the read and unread conditions, and counterbalanced the order of administration of the read and unread conditions.

\section{Design}

The experiment was a mixed-factors design. The between-subjects factors were headings condition (none, section, content, and structure) and three counterbalancing factors (assignment of texts to the read vs. unread condition; order of read and unread conditions; assignment of the target questions to the first vs. fifth position). The within-subjects factors were reading condition (read vs. unread) and question (first vs. fifth).

\section{Coding}

The videotaped sessions were coded as follows. For each participant, each turn of a page was termed a look, and each separate look was scored for (1) the identity of the page that was examined and (2) the length of time of the look. Time per look was operationally defined as the time between page turns, where the initiation of a look was defined as the point in time where the last-examined page fell horizontally in the notebook.

Two reliability checks were made on a randomly selected $20 \%$ of the participants. One reliability check was done on the measurement of time per look. Almost all of the variance in the look times was due to systematic differences across the pages $\left(\omega^{2}=.99\right)$. A second check demonstrated $99 \%$ accuracy in recording the order in which pages were viewed.

\section{RESULTS}

Because our primary interest was in the possibility that searchers use different strategies for finding target information in a text, we chose dependent variables that would provide a comprehensive profile of search behavior. For each of the four searches by a participant, four sets of dependent variables were created to measure different aspects of the search process. First, two global measures of search efficiency were recorded. Total search time was the time it took to complete the search, measured from when the participant opened the test booklet to when the participant pointed to the target sentence. Total turns was defined as the number of page turns made during a search. Second, look time was the sole measure of page inspection. This was defined as the mean time per look computed across all the separate looks at the text during a search. Third, the starting location of a search was assessed by recording the pages corresponding to the first and second look at the text (look 1 and look 2). Finally, the distribu- tion of movements during page turning was assessed by three variables. Singles were defined as the proportion of all page turns that were single-page advances. Jumps were defined as the proportion of all page turns that were advances of more than one page. Turnbacks were defined as the proportion of all page turns that were made to a previous page in the text.

Two sets of analyses were conducted on the search data. First, cluster analyses were conducted to identify distinct search strategies. Second, conventional analyses of variance (ANOVAs) were conducted on the individual search measures in order to summarize the effects of the three independent variables.

\section{Cluster Analyses \\ Identification of Different Search Strategies}

Cluster analyses group together cases (i.e., individual searches) with similar profiles on a set of dependent variables and distinguish groups that differ in their mean profile. Thus, they provide a potential means of inducing distinct search strategies. Each of the dependent variables was included in the analysis, except for total time. ${ }^{1}$ All variables were converted to standard scores so that they would receive equal weighting in the analysis. The 501 individual searches (i.e., 4 searches per participant $X$ 128 participants -11 damaged files $=501$ cases) were then analyzed using Ward's hierarchical clustering method (Aldenderfer \& Blashfield, 1984). A five-cluster solution was adopted as the best account of the data; distinguishing a sixth cluster resulted in only five cases being assigned to the new cluster. Characteristics of the five clusters are presented in Table 2.

All five of the clusters are readily interpretable. In the hierarchical solution, Clusters A, B, and C group together and are distinguished from Clusters D and E. Clusters $A$ and $B$ are nearly identical with respect to how pages were searched. In both clusters, readers began on the first page and advanced page by page until they had reached the target page; there were virtually no advances of more than one page at a time (i.e., jumps) and very few turnbacks. The only distinction between the two clusters occurred with respect to look time. The searches grouped into Cluster $\mathrm{A}$ all involved much shorter examinations of each page than did the searches grouped into Cluster B. Cluster C was grouped with Clusters A and B because all three clus-

Table 2

Means and Standard Deviations on Seven Variables for Five Clusters

\begin{tabular}{|c|c|c|c|c|c|c|c|c|c|c|}
\hline \multirow[b]{3}{*}{ Variable } & \multicolumn{10}{|c|}{ Cluster } \\
\hline & \multicolumn{2}{|c|}{$\mathrm{A}(n=264)$} & \multicolumn{2}{|c|}{$B(n=29)$} & \multicolumn{2}{|c|}{$C(n=109)$} & \multicolumn{2}{|c|}{$D(n=40)$} & \multicolumn{2}{|c|}{$E(n=59)$} \\
\hline & $M$ & $S \bar{D}$ & $M$ & $S D$ & $M$ & $S D$ & $M$ & $S D$ & $M$ & $S D$ \\
\hline Look 1 & 1.171 & 0.712 & 1.345 & 1.857 & 5.936 & 2.773 & 6.500 & 2.935 & 12.644 & 1.595 \\
\hline Look 2 & 2.080 & 0.749 & 1.966 & 1.802 & 7.257 & 2.529 & 10.225 & 2.851 & 12.475 & 1.331 \\
\hline Total turns & 11.833 & 4.366 & 11.483 & 3.491 & 6.092 & 3.555 & 3.550 & 1.484 & 3.593 & 3.058 \\
\hline Single & 0.946 & 0.082 & 0.948 & 0.185 & 0.828 & 0.183 & 0.216 & 0.200 & 0.235 & 0.245 \\
\hline Jumps & 0.012 & 0.032 & 0.003 & 0.016 & 0.100 & 0.122 & 0.507 & 0.234 & 0.012 & 0.036 \\
\hline Turnbacks & 0.041 & 0.069 & 0.049 & 0.054 & 0.072 & 0.124 & 0.276 & 0.230 & 0.753 & 0.360 \\
\hline Look time & 4606 & 2425 & 17,173 & 5463 & 4250 & 2642 & 5664 & 4050 & 5038 & 3025 \\
\hline
\end{tabular}


ters involved a high proportion of single-page advances and correspondingly low proportions of jumps and turnbacks. However, Cluster $\mathrm{C}$ shares many similarities with Clusters D and E.

Clusters C, D, and E are distinct from clusters A and B in two general respects. First, searches grouped into these clusters did not begin on the first page. Second, these searches were more efficient than those in Clusters A and $B$ in the sense that they involved fewer page turns. In addition, Clusters $\mathrm{D}$ and $\mathrm{E}$ are characterized by having a much lower proportion of single-page advances than those for Clusters A, B, and C.

If we compare Clusters $\mathrm{C}, \mathrm{D}$, and $\mathrm{E}$ with each other, a few distinctions can be noted. Clusters $\mathrm{C}$ and $\mathrm{D}$ comprise searches that were initiated in the middle of the text, whereas searches in Cluster $E$ were initiated at the end of the text. Most of the page turns in Cluster $\mathrm{C}$ consisted of single-page advances, with the consequence that the total number of page turns was greater in Cluster $\mathrm{C}$ searches than in Cluster D or Cluster E searches. Most of the page turns in Cluster D consisted of forward jumps of two or more pages, but turnbacks and single-page advances were also common. Finally, page turns in Cluster E consisted mostly of turnbacks.

We believe that the five clusters should be interpreted as strategies that searchers consciously employ to locate the answer to a question. Therefore, we would expect to find that searchers choose different strategies under different experimental conditions. In addition, to the extent that the experimental manipulations did not account for all of the variation in strategy use, we would expect to find that individuals exhibit consistency in their strategy preferences.

\section{Effects of Experimental Condition on Search Strategies}

Effects of prior exposure. Table 3 demonstrates that participants' prior experience with a text influenced how they searched the text. ${ }^{2}$ When they had no previous exposure to the text (i.e., search 1, unread), the participants began searching on the first page and advanced page by page until the target page was encountered (i.e., Clusters $A$ and $B$ ). The only distinction between the search strategies used in the search 1, unread condition occurred in the amount of time searchers spent examining each page.

When the participants had searched the text several times (i.e., search 5, unread) or had read the text prior to the first search (i.e., search 1, read), a slight majority of

Table 3

Frequency of Cluster Assignments as a Function of Search and Read

\begin{tabular}{lrrrrr} 
& \multicolumn{5}{c}{ Cluster } \\
\cline { 2 - 6 } \multicolumn{1}{c}{ Condition } & A & \multicolumn{1}{c}{ B } & \multicolumn{1}{c}{ C } & D & E \\
\hline Search 1, Unread & 92 & 27 & 1 & 0 & 0 \\
Search 5, Unread & 69 & 0 & 34 & 12 & 11 \\
Search 1, Read & 69 & 1 & 26 & 14 & 18 \\
Search 5, Read & 34 & 1 & 48 & 14 & 30 \\
\hline
\end{tabular}

them still used the strategy represented by Cluster A. However, only 1 participant used the Cluster B strategy, and a large minority of the participants used one of the more efficient strategies represented by Clusters $C, D$, and $E$.

Finally, the participants with the most exposure to the text (i.e., search 5, read) differed from the other conditions in that a minority of them used a page-by-page search (Cluster A or B). Rather, most of the searches were initiated from the middle or end of the text, with the most commonly used strategy being that represented by Cluster C.

In short, as searchers became increasingly familiar with the content and structure of the text, they were increasingly likely to use strategies that relied on knowledge of the approximate page location of the target information.

Effects of headings. Table 4 illustrates that the effects of headings on search strategies depended on whether the participants had previously read and/or searched the text. In Table 4, search strategies are divided into those that involve a page-by-page, exhaustive search (i.e., Clusters A and B) and those that are more selective (i.e., Clusters C, D, and E), and the search 1, unread condition (i.e., prior exposure $=n o$ ) is compared with the three conditions involving reading and/or prior searching of the text (i.e., prior exposure $=y e s$ ).

Table 4 again shows that virtually all participants used a page-by-page search when they had no knowledge of the text's topic structure or content, but that many participants used a more selective search strategy when they had some prior exposure to the text. The important new information is that the shift to a selective search strategy was most pronounced for the participants in the no-headings condition. Analyses of look times in the search 1, unread condition (reported under Analyses of the Experimental Design below, and illustrated in Table 6) show that the participants in the no-headings condition examined the text more closely than did the participants in the other heading conditions. Evidently, their closer attention meant that they learned more about the content and structure of the text and consequently more likely to develop a pageskipping strategy that capitalized on this knowledge.

\section{Individual Differences in Strategy Preferences}

If the clusters represent distinct search strategies, we would expect to find individual differences in strategy preferences under those conditions where the demands of the search situation allow some flexibility in strategy choice. In order to assess this, we analyzed the data for the three conditions involving prior exposure to the text. We excluded the data from Cluster B because it contributed only two observations to this data set. In addition, only data from participants who contributed observations to all three conditions were included in the analysis $(n=$ 125 ), so the cell frequencies for the analysis differed slightly from those displayed in Table 3 .

Within each of the three conditions, we first computed the proportion of observations assigned to four clusters. These observed proportions were then used to compute the proportion of participants who would be predicted to 
Table 4

Frequency of Cluster Assignments as a Function of Prior Exposure to the Text and Type of Heading

\begin{tabular}{clcc}
\hline & & \multicolumn{2}{c}{ Clusters } \\
\cline { 3 - 4 } Prior Exposure? & Headings & A \& B & C, D \& E \\
\hline \multirow{2}{*}{ No } & Structure & 30 & 0 \\
& Content & 28 & 1 \\
& Section & 31 & 0 \\
& None & 30 & 0 \\
Yes & Subtotal & 119 & 1 \\
& Structure & 46 & 49 \\
& Content & 45 & 52 \\
& Section & 53 & 42 \\
& None & 30 & 64 \\
& Subtotal & 174 & 207 \\
\hline
\end{tabular}

be assigned to each possible combination of clusters across the three experimental conditions, assuming that cluster assignments were independent. For example, the proportion of participants assigned to Cluster $\mathrm{C}$ was .272 in condition search 5, unread; 208 in search 1, read; and .384 in condition search 5 , read. If we take the product of these three proportions, the expected proportion of participants assigned to Cluster $\mathrm{C}$ in all three conditions was .0217 . The expected proportion of participants assigned to each possible combination of clusters was computed and used to calculate the proportion of participants who would be predicted to be assigned one, two, or three different clusters across the three experimental conditions. The predicted and observed distributions are presented in Table 5. It can be seen that the distributions differ $\left[\chi^{2}(2, N=125)=27.80, p<.01\right]$. Specifically, the number of participants assigned to the same cluster across all three conditions is higher than expected under the independence assumption $\left[\chi^{2}(1, N=125)=27.45, p<.01\right]$. In sum, although familiarity with the text heavily influenced a searcher's choice of page-turning strategy, individuals also were influenced by consistent personal preferences with respect to how to search.

\section{Analyses of the Experimental Design}

In addition to the cluster analyses, ANOVAs were conducted on each of the dependent variables, including total time. The findings from these analyses can largely be anticipated from knowledge of how the cluster assignments varied as a function of the read, search, and headings variables. Indeed, we think of the effects on the individual dependent variables as being mediated by their effects on the participants' search strategies, as represented by the clusters. Therefore, the results of these analyses will be summarized.

To begin with, despite the fact that the headings, search, and read variables were orthogonally manipulated, the experimental design was divided into two sections for purposes of presentation. This is justified because separate ANOVAs of the individual variables produced three-way interactions of the read, search, and headings factors for all variables except look time. In all cases, the effects of headings were different in the search 1 , unread condition than in the three conditions involving prior text exposure.

\section{Search With No Prior Exposure to the Text}

In the analyses of the search 1, unread condition, there were two between-subjects factors of headings and a counterbalancing variable involving text assignment. In addition, the analysis of the starting location of the search included a within-subjects factor because the dependent variable involved repeated measures (i.e., look 1 and look 2). ${ }^{3}$ In all reported tests, the level of significance is .05 unless noted otherwise. When pairwise comparisons were conducted on the means of the headings conditions, Tukey's HSD procedure was used to control familywise error rate.

The results for the search 1, unread condition are displayed in the first column of Table 6 . Type of heading had reliable effects on total search time $[F(3,114)=3.29$, $\left.M S_{\mathrm{e}}=8,570\right]$, with search being faster in the content headings condition than in the no-headings condition. The effect of headings on total time was largely due to look time $\left[F(3,112)=7.09, M S_{\mathrm{e}}=23,041,761\right]$. Looks were shorter in the content headings condition than in the section or no-headings conditions and shorter in the structure headings condition than in the no-headings condition.

Given that all participants used a page-by-page search strategy (see Table 3), headings did not influence the starting location of the search (i.e., look 1 or look 2) or the distribution of single-page advances or jumps. Surprisingly, however, there was an effect of headings on the total number of page turns $\left[F(3,112)=3.36, M S_{\mathrm{e}}=\right.$ 18.05]. Table 6 shows that more turns tended to be made in the structure condition than in the section and noheadings conditions, although only the difference between the structure and no-headings condition was statistically reliable. In both the structure and content headings conditions, there was a tendency for searchers to make more turnbacks than in the section and no-headings conditions $\left[F(3,112)=2.36, M S_{\mathrm{e}}=0.005, .05<p<.1\right]$. In addition, we performed a post hoc analysis in which we tabulated the number of times searchers reexamined a page they had previously inspected. In fact, headings affected the number of reexaminations $\left[F(3,110)=3.13, M S_{\mathrm{e}}=\right.$ $15.31]$, and the pattern of means mirrored that for the total number of page turns. Thus, the effects of headings on total turns appears to be due to searchers in the structure

Table 5

Predicted and Observed Distributions of Number of Different Cluster Assignments

\begin{tabular}{cccc}
\hline $\begin{array}{c}\text { No. of Different } \\
\text { Cluster Assignments }\end{array}$ & $\begin{array}{c}\text { Expected } \\
\text { Proportion }\end{array}$ & $\begin{array}{c}\text { Expected } \\
\text { Frequency }\end{array}$ & $\begin{array}{c}\text { Observed } \\
\text { Frequency }\end{array}$ \\
\hline 1 & .1096 & 13.7006 & 32 \\
2 & .6138 & 76.7221 & 67 \\
3 & .2766 & 34.5772 & 26 \\
Sum & 1.000 & 125 & 125 \\
\hline
\end{tabular}


Table 6

Means for Eight Measures of Search Presented as a Function of Experimental Condition

\begin{tabular}{|c|c|c|c|c|c|}
\hline Variable & Headings & $\begin{array}{c}\text { Search 1, } \\
\text { Unread }\end{array}$ & $\begin{array}{c}\text { Search 5, } \\
\text { Unread }\end{array}$ & $\begin{array}{c}\text { Search 1, } \\
\text { Read }\end{array}$ & $\begin{array}{c}\text { Search } 5, \\
\text { Read } \\
\end{array}$ \\
\hline \multirow[t]{5}{*}{ Total Time (sec) } & Structure & 134.74 & 49.33 & 31.21 & 29.41 \\
\hline & Content & 91.47 & 46.93 & 34.37 & 24.35 \\
\hline & Section & 149.35 & 68.77 & 50.71 & 35.70 \\
\hline & None & 162.70 & 49.29 & 33.69 & 27.33 \\
\hline & $M$ & 134.57 & 53.58 & 37.50 & 29.20 \\
\hline \multirow[t]{5}{*}{ Look Time (msec) } & Structure & 7,540 & 4,454 & 3,439 & 4,188 \\
\hline & Content & 5,885 & 4,091 & 3,340 & 3,848 \\
\hline & Section & 9,718 & 6,155 & 4,680 & 4,754 \\
\hline & None & 11,170 & 5,523 & 4,086 & 4,052 \\
\hline & $M$ & 8,578 & 5,056 & 3,886 & 4,211 \\
\hline \multirow[t]{5}{*}{ Look 1 (page no.) } & Structure & 1.00 & 4.31 & 3.59 & 6.03 \\
\hline & Content & 1.14 & 3.94 & 3.94 & 7.25 \\
\hline & Section & 1.03 & 3.06 & 3.22 & 6.65 \\
\hline & None & 1.00 & 5.40 & 4.66 & 7.13 \\
\hline & $M$ & 1.04 & 4.18 & 3.85 & 6.77 \\
\hline \multirow{5}{*}{ Look 2 (page no.) } & Structure & 1.70 & 5.53 & 5.19 & 7.41 \\
\hline & Content & 1.93 & 4.72 & 4.91 & 8.19 \\
\hline & Section & 1.71 & 4.50 & 4.59 & 7.71 \\
\hline & None & 1.70 & 6.73 & 5.84 & 8.19 \\
\hline & $M$ & 1.76 & 5.37 & 5.13 & 7.88 \\
\hline \multirow[t]{5}{*}{ Singles (proportion) } & Structure & .915 & .757 & .743 & .687 \\
\hline & Content & .917 & .765 & .759 & .503 \\
\hline & Section & .947 & .885 & .833 & .652 \\
\hline & None & .956 & .691 & .660 & .721 \\
\hline & $M$ & .934 & .775 & .749 & .641 \\
\hline \multirow[t]{5}{*}{ Jumps (proportion) } & Structure & .013 & .060 & .132 & .081 \\
\hline & Content & .013 & .097 & .078 & .098 \\
\hline & Section & .004 & .037 & .084 & .077 \\
\hline & None & .013 & .113 & .128 & .081 \\
\hline & $M$ & .011 & .077 & .106 & .084 \\
\hline \multirow[t]{5}{*}{ Turnbacks (proportion) } & Structure & .072 & .152 & .125 & .201 \\
\hline & Content & .070 & .107 & .163 & .337 \\
\hline & Section & .049 & .078 & .083 & .206 \\
\hline & None & .031 & .163 & .149 & .198 \\
\hline & $M$ & .056 & .125 & .130 & .236 \\
\hline \multirow[t]{5}{*}{ Total No. Turns } & Structure & 14.63 & 9.19 & 7.97 & 6.91 \\
\hline & Content & 12.62 & 10.84 & 8.47 & 5.84 \\
\hline & Section & 12.00 & 9.72 & 8.25 & 6.13 \\
\hline & None & 11.40 & 7.53 & 6.63 & 5.53 \\
\hline & $M$ & 12.66 & 9.32 & 7.83 & 6.10 \\
\hline
\end{tabular}

and content headings conditions inspecting pages somewhat superficially and, therefore, occasionally missing target information and having to reinspect previously examined pages.

In sum, headings had no influence on the page-turning strategy used when searchers had no knowledge of the text, but headings did influence the inspection of a page once it was selected for examination. If the text contained headings that provided content information (i.e., structure or content headings), pages were inspected quickly but superficially, with the consequence that searchers had to reexamine pages more often. Nonetheless, searchers who received structure or content headings were still faster at locating target information than searchers who received section headings or no headings.

\section{Search With Prior Exposure to the Text}

The analyses of data from the three conditions involving prior exposure to the text paralleled the analyses for the search 1, unread condition, except for the addition of the within-subjects factor of type of exposure (search 5, unread; search 1, read; search 5 , read). The results for the three conditions are summarized in the last three columns of Table 6. Before turning to comparisons among these conditions, the reader should note the substantial differences between the search 1 , unread condition and these three conditions. The pattern of differences across the dependent variables reflects the shift from the exclusive use of an exhaustive search strategy in the search 1 , unread condition to increasingly frequent use of a selective search strategy with more exposure to the text.

Effects of prior exposure. Within the three conditions involving reading and/or prior searching of the text, there were systematic differences between the conditions in total search time $\left[F(2,236)=24.45, M S_{\mathrm{e}}=777\right]$, mean look time $\left[F(2,234)=6.26, M S_{\mathrm{e}}=7,703,141\right]$, starting location of the search $\left[F(2,234)=24.63, M S_{\mathrm{e}}=23.87\right]$, proportion of single-page advances $[F(2,234)=5.61$, 
$\left.M S_{\mathrm{e}}=0.098\right]$, and proportion of turnbacks $[F(2,234)=$ $\left.7.18, M S_{\mathrm{e}}=0.055\right]$. The only variables that were not influenced by the type of prior exposure were the total number of page turns and the proportion of jumps.

Generally, the effects of prior exposure were that search became more efficient as searchers became more familiar with the text. Total search time decreased from search 5, unread $(M=53.58 \mathrm{sec})$ to search $1, \operatorname{read}(M=37.50 \mathrm{sec})$ to search 5 , read $(M=29.20 \mathrm{sec})$, although the latter difference was only marginally significant when familywise error rate was controlled. The decrease in total search time with increasing familiarity was due partly to effects of familiarity on page inspection. Mean look time was longer in the search 5 , unread condition $(M=5.06 \mathrm{sec})$ than in the search 1 , read condition $(M=3.89 \mathrm{sec})$ or search 5, read condition $(M=4.21 \mathrm{sec})$; the latter two conditions did not differ reliably. Finally, total search time decreased as familiarity increased because searchers' page-turning strategies became more selective. The participants in the search 5, read condition began their search closer to the target page than the participants in the other two conditions, which did not differ. This difference in the starting location of the search resulted in differences in the distribution of page turns. The participants in the search 5 , read condition made proportionately more turnbacks and fewer single-page advances than did the participants in the other two conditions; the search 5, unread and search 1 , read conditions were indistinguishable with respect to page-turning strategies.

Effects of headings. There were few differences among the conditions with respect to the effects of headings. First, Table 6 shows that total search time was affected by the type of heading $\left[F(3,118)=5.59, M S_{\mathrm{e}}=\right.$ $1,037]$. Search time was slower in the section headings condition $(51.73 \mathrm{sec})$ than in each of the other three conditions, which did not differ (structure $=36.65 \mathrm{sec}$, content $=35.22 \mathrm{sec}$, none $=36.77 \mathrm{sec})$. Note how different this pattern is from the effect of headings in the search 1 , unread condition.

Second, look time was affected by headings $[F(3,117)=$ $\left.3.88, M S_{\mathrm{e}}=9,582,208\right]$. Pairwise comparisons demonstrated that look times were shorter in the content headings condition than in the section headings condition. In addition, a post hoc contrast showed that look time was faster, on the average, in the structure and content headings conditions $(M=3.89 \mathrm{sec})$ than in the section and no-headings conditions $(M=4.88 \mathrm{sec}), t(117)=3.01$, $S E=0.33$ ]. In this sense, the effect of headings is similar to that found in the search 1, unread condition; a difference, however, is that look time was particularly slow when section headings were present and the participants had some familiarity with the text.

Finally, the effect of headings on single-page advances varied with type of prior exposure $[F(6,234)=2.36$, $\left.M S_{\mathrm{e}}=0.098\right]$. Table 6 shows that the effect of headings was the same for the search 5 , unread condition and the search 1 , read condition $[F(3,118)<1]$; however, these two conditions differed markedly from the search 5 , read condition $\left[F(3,117)=4.14, M S_{\mathrm{e}}=0.081\right]$.

\section{DISCUSSION}

Our first goal was to identify distinct strategies for the simple text search task investigated in this study. Because no theoretical framework currently exists that might guide hypothesizing about search strategies, an inductive approach was taken in order to identify search strategies. A battery of measures was selected to provide a comprehensive picture of search; cluster analyses were used to identify five distinct profiles on the battery. We interpret the clusters as distinct search strategies and support this interpretation with three observations. First, the profiles of means for each cluster (see Table 2) are readily interpretable as sensible strategies for searching the texts in our experiment. Second, the distribution of cluster assignments as a function of prior exposure (see Table 3) is also sensible. Namely, as searchers become more familiar with the text, they are increasingly likely to adopt a page-skipping strategy. Finally, the distribution of cluster assignments across individuals is not random. Rather, there is a reliable tendency for individuals to maintain the same strategy across all three conditions involving some prior exposure to the text (see Table 5).

Given that we were successful in identifying different search strategies, our second goal was to determine how the selection of a search strategy depended on the searcher's knowledge of the text. The effects of the reading manipulation and the number of searches provide most of the information relevant to this question.

\section{Effects of Familiarity}

With no prior exposure to the text, searchers took an average of $135 \mathrm{sec}$ to find the target information; after reading the text and searching it several times, searchers took an average of only $29 \mathrm{sec}$. Part of this familiarity effect was due to searchers' spending less time examining the pages that they had chosen to inspect (i.e., look time). This result is consistent with the repeated finding that readers speed up across successive readings of the same text under the same task goals (e.g., Hyönä \& Niemi, 1990; Levy et al., 1995; Millis et al., 1998; Whittlesea, 1990). In fact, the mean look time in the search 1 , read condition was less than half that in the search 1 , unread condition, which is a proportionately much greater time savings than that found in rereading experiments. This suggests that searchers' memories for text content is sufficiently detailed so that sampling just some of a page's content (i.e., skimming) allows an accurate prediction that the target is not present on the page (Masson, 1982, 1983).

The other reason that familiarity reduced total search time was that it promoted efficient page turning strategies. With no familiarity with the text, all searchers used a page-by-page, exhaustive search strategy; as familiarity increased, searchers were more likely to adopt some type of page-skipping strategy. Thus, searchers developed a text representation that effectively guided their computation of the approximate location of the target information.

We interpret the pattern of familiarity effects as support for the general hypothesis that reading and/or search- 
ing a text results in a representation of the text's topics and their organization (Hyönä, 1995; Lorch et al., 1985), which is used to guide text search. This hypothesis can account for the effects of familiarity on both page inspection and page turning. First, knowledge of text topics facilitates page inspection by supporting a page-skimming strategy. A searcher would need to inspect only parts of a page to identify its topics and evaluate whether the target information is likely to be found on that page. Second, knowledge of topic organization guides a pageskipping strategy by supporting an accurate prediction of the approximate page on which the target is likely to be found.

Can the effects of familiarity be explained without the hypothesis that search is guided by a topic structure representation? Perhaps exposure to the text results only in detailed (implicit) memory for the microstructure of the text. If so, skimming parts of a page might be a sufficient reminder of page contents to evaluate whether the page is likely to contain the target information. Thus, the hypothesis may be able to explain the effects of familiarity on page inspection (i.e., look times). However, it is unclear how a representation that does not include information about the text's macrostructure might guide an efficient page turning strategy.

\section{Effects of Headings}

In contrast to familiarity, headings had relatively little effect on search strategies. One reason that headings were manipulated in the experiment was that headings have been shown to influence readers' representations of a text's topic structure when they are reading in order to summarize or recall the text (Lorch \& Lorch, 1996a, 1996b; Lorch et al., 1993). On the basis of these results, it was anticipated that the presence of headings in a text would promote the use of page-skipping strategies in a search task. In fact, if headings had any effect, it was to interfere with the use of page-skipping strategies (see Table 4). At first glance, this outcome appears to be at odds with demonstrations that headings encourage the construction of a topic structure representation (Lorch \& Lorch, 1996a, 1996b; Lorch et al., 1993). However, those demonstrations involved tasks that placed great demands on memory (e.g., recall and summarization). In such tasks, readers may use headings to construct a topic structure representation in anticipation of using the representation to guide memory retrieval. However, in a search task, readers appear to use the headings on a page for a different purpose-namely, to facilitate the inspection of the page. This use of headings benefits page inspection but at the cost of interfering with the construction of a topic structure representation.

Although headings had only small effects on pageturning strategies, they had clear effects on page inspection (i.e., look time). These effects are relevant to the question of which of the three potential functions of headings influence search. Because headings demarcate subsections of a text, searchers may use them to guide the process of sampling content from a page. The effects of section headings suggest that searchers do use headings in this way. Specifically, section headings slowed the search process when the searcher had some familiarity with the text. This result may well be specific to the texts used in this study, both of which had several headings on every page. In a less frequently divided text, a sampling process guided by headings may well speed the search process. In any event, the data demonstrate that searchers do attend to the demarcating function of headings.

Searchers also use the topic information in headings, as is demonstrated by the finding that content and structure headings produced shorter page inspections than section headings and no headings did. If it is assumed that searchers also used content and structure headings to guide the sampling of content from a page, the facilitating effect of topic labels is particularly impressive. The availability of topic information in headings would support an efficient skimming strategy because, in the case of the critical targets, they were good predictors of the location of the target information. Evidence that headings were used to guide page skimming comes from the findings that page inspections were relatively fast and that searchers were more likely to miss the target when headings contained topic labels than when they did not.

Finally, there was no evidence that searchers used information about the hierarchical organization of the text to guide their page inspection. If they had, look times should have been shorter in the structure headings condition than in the content headings condition; in fact, there was a consistent tendency in the opposite direction.

The finding that searchers found topic information in headings helpful in their page inspections may explain the unexpected outcome that headings tended to prevent the development of page-skipping strategies. First, the use of a page-skimming strategy would probably interfere with the construction of a topic structure representation that might guide a page-skipping strategy. Second, if searchers believe (accurately or inaccurately) that they are searching each page efficiently, they may be unwilling to expend the necessary effort to plan each successive page turn (Garner, 1990). Finally, searchers might prefer an effective page-skimming strategy to a page-skipping strategy because they believe that a page-by-page search is a more reliable method for finding the target information.

\section{Conclusion}

The search task in our experiment was very rudimentary. Despite the simple task, searchers used a variety of sensible strategies for finding information. When the text was unfamiliar, they used an exhaustive, page-by-page search; as the text became familiar, they used more selective, page-skipping search strategies. The page-skipping strategies demonstrate that reading and/or searching a text results in a text representation that includes information about the text topics and their organization.

We conclude by suggesting that an inductive approach, like the one exemplified here, would be useful in study- 
ing strategic behavior in many domains--particularly, domains that lack an adequate empirical foundation on which to base theorizing about strategies.

\section{REFERENCES}

Aldenderfer, M. S., \& Blashfield, R. K. (1984). Cluster analysis (Sage University Paper Series on Quantitative Applications in the Social Sciences, No. 07-044). Beverly Hills, CA: Sage.

Carr, T. H., Brown, J. S., \& Charalambous, A. (1989). Repetition and reading: Perceptual encoding mechanisms are very abstract but not very interactive. Journal of Experimental Psychology: Learning, Memory, \& Cognition, 15, 763-779.

DREHER, M. J. (1992). Searching for information in textbooks. Journal of Reading, 35, 364-371.

Dreher, M. J., \& GuthrJe, J. T. (1987). Cognitive processes in textbook chapter search tasks. Reading Research Quarterly, 25, 323-339.

Dreher, M. J., \& GuThrie, J. T. (1990). Cognitive processes in textbook chapter search tasks. Reading Research Quarterly, 25, 323-339.

Dreher, M. J., \& Sammons, R. B. (1994). Fifth graders' search for information in a textbook. Journal of Reading Behavior, 26, 301-313.

GARNER, R. (1990). When children and adults do not use learning strategies: Toward a theory of settings. Review of Educational Research, 60, 517-529.

GeRNSBACHER, M. A. (1990). Language comprehension as structure building. Hillsdale, NJ: Erlbaum.

Gernsbacher, M. A. (1997). Two decades of structure building. Discourse Processes, 23, 265-304.

GUTHRIE, J. T. (1988). Locating information in documents: Examination of a cognitive model. Reading Research Quarterly, 23, 178-199.

Guthrie, J. T., BritTen, T., \& Barker, K. G. (1991). Roles of document structure, cognitive strategy, and awareness in searching for information. Reading Research Quarterly, 26, 300-324.

GUthrie, J. T., SiefERT, M., \& KirSCh, I. S. (1986). Effects of education, occupation, and setting on reading practice. American Educational Research Journal, 23, 151-160.

HARTLEY, J., \& TRUEMAN, M. (1985). A research strategy for text designers: The role of headings. Instructional Science, 14, 99-155.

HYÖNÄ, J. (1995). An eye movement analysis of topic-shift effect during repeated reading. Journal of Experimental Psychology: Learning, Memory, \& Cognition, 21, 1365-1373.

HYÖNÄ, J., \& NiEMI, P. (1990). Eye movements in repeated reading of a text. Acta Psychologica, 73, 259-280.

KINTSCH, W., \& VAN DIJK, T. A. (1978). Toward a model of discourse comprehension and production. Psychological Review, 85, 363-394.

Levy, B. A., Barnes, L., \& Martin, L. (1993). Transfer of fluency across repetitions and across texts. Canadian Journal of Psychology, 47, 401-427.

Levy, B. A., \& Burns, K. I. (1990). Reprocessing text: Contributions from conceptually driven processes. Canadian Journal of Psychology, 44, 465-482.

Levy, B. A., Campsall, J., Browne, J., Cooper, D., Waterhouse, C., \& WILSON, C. (1995). Reading fluency: Episodic integration across texts. Journal of Experimental Psychology: Learning, Memory, \& Cognition, 21, 1169-1185.

Levy, B. A., Masson, M. E. J., \& ZoubeK, M. A. (1991). Rereading texts: Words and their context. Canadian Journal of Psychology, 45, 492-506.

LORCH, R. F., JR. (1989). Text signaling devices and their effects on reading and memory processes. Educational Psychology Review, 1, 209-234.

LORCH, R. F., JR., \& LORCH, E. P. (1995). Effects of organizational signals on text processing strategies. Journal of Educational Psychology, 87, 537-544.

LORCH, R. F., JR., \& LORCH, E. P. (1996a). Effects of headings on text recall and summarization. Contemporary Educational Psychology, 21, 261-278

LORCH, R. F., JR., \& LORCH, E. P. (1996b). Effects of organizational signals on free recall of expository text. Journal of Educational Psychology, 88, 38-48.
LORCH, R. F., JR., LORCh, E. P., INMAN, W. E. (1993). Effects of signaling topic structure on text recall. Journal of Educational Psychology, 85, 281-290.

Lorch, R. F., JR., LoRch, E. P., \& Matthews, P. D. (1985). On-line processing of the topic structure of a text. Journal of Memory \& Language, 24, 350-362.

LoRCH, R. F., JR., LoRCH, E. P., \& Mogan, A. M. (1987). Task effects and individual differences in on-line processing of the topic structure of a text. Discourse Processes, 10, 63-80.

Masson, M. E. J. (1982). Cognitive processes in skimming stories. Journal of Experimental Psychology: Learning, Memory, \& Cognition, $\mathbf{8}$, 400-417.

Masson, M. E. J. (1983). Conceptual processing of text during skimming and rapid sequential reading. Memory \& Cognition, 11, 262-274.

MAYER, R. E. (1983). Can you repeat that? Qualitative effects of repetition and advance organizers on learning from science prose. Journal of Educational Psychology, 75, 40-49.

McGoldrick, J. A., Martin, J., Bergering, A. J., \& Symons, S. (1992). Locating discrete information in text: Effects of computer presentation and menu formatting. Journal of Reading Behavior, 24, 1-19.

MiKULECKY, L. (1982). Job literacy: The relationship between school preparation and workplace actuality. Reading Research Quarterly, 17, 400-419.

Millis, K. K., Simon, S., \& TENBroek, N. S. (1998). Resource allocation during the rereading of scientific texts. Memory \& Cognition, 26, 232-246.

RANEY, G. E., \& RAYNER, K. (1995). Word frequency effects and eye movements during two readings of a text. Canadian Journal of Psychology, 49, 151-172.

Rayner, K., Raney, G. E., \& Pollatsek, A. (1995). Eye movements and discourse processing. In R. F. Lorch, Jr., \& E. J. O'Brien (Eds.), Sources of coherence in reading (pp. 9-35). Hillsdale, NJ: Erlbaum.

STICHT, T. (1975). Reading for working. Alexandria, VA: Human Resources Research Organization.

Symons, S., \& Pressley, M. (1993). Prior knowledge affects text search success and extraction of information. Reading Research Quarterly, 28, 251-259.

SYMONS, S., \& SPECHT, J. A. (1994). Including both time and accuracy in defining text search efficiency. Journal of Reading Behavior, 26, 267-276.

WhittLesea, B. W. A. (1990). Perceptual encoding mechanisms are tricky but may be very interactive: Comment on Carr, Brown, and Charalambous (1989). Journal of Experimental Psychology: Learning, Memory, \& Cognition, 16, 727-730.

Yussen, S. R., Stright, A. D., \& Payne, B. (1993). Where is it? Searching for information in a college textbook. Contemporary Educational Psychology, 18, 240-257.

\section{NOTES}

1. Total time was excluded because it was almost completely redundant with two other measures. Namely, it corresponds to the product of total turns and look time, plus time spent inspecting the question.

2. No inferential statistics were conducted on any of the contingency tables relating the distribution of clusters to experimental variables. $\mathrm{Al}$ though chi-square tests might appear appropriate, each participant contributed four searches to the experiment so observations across cells in the contingency tables are not independent. Despite the lack of statistical tests, it seems safe to offer some conclusions from these data.

3. In each analysis of variance, all single degree of freedom tests should have been against an error term based on $120 \mathrm{df}$. However, the data files for 11 searches were damaged and the data were lost. As a result, the error $d f$ are always less than the theoretical maximum and they vary slightly (i.e., from 112 to 118 for single $d f$ tests), depending on the particular comparison being made.

(Manuscript received June 4, 1998 revision accepted for publication June 20, 1999.) 